\title{
REFLECTIONS ON AIR CAPTURE: THE POLITICAL ECONOMY OF ACTIVE INTERVENTION IN THE GLOBAL ENVIRONMENT
}

\author{
An Editorial Comment
}

When global climate change came onto domestic and international policy agendas in the late 1980s, only two types of response were initially considered: reducing emissions by improving efficiencies or switching to lower or non-carbon energy sources; and adapting to the anticipated changes. Since that time the agenda of potential responses has been progressively expanded, principally by adding various ways to intervene in the global carbon cycle or the climate to break the connection between emissions of greenhouse gases and the resultant climate changes. ${ }^{1}$ Three types of these "intervening" responses are now, to varying degrees, present in policy debate: biological sequestration of carbon in forests or soils (Schlamadinger and Marland, 2000); point-source carbon capture from fossil fuels or combustion gases, followed by sequestration in stable reservoirs (Parson and Keith, 1997); and various forms of albedo modification or other direct manipulation of the climate system, collectively called geoengineering (Keith, 2000).

In this issue of Climatic Change, Keith, Ha-Duong, and Stolaroff (2006) propose that one additional intervening option should be considered: capturing $\mathrm{CO}_{2}$ directly from the atmosphere, then sequestering it in the same reservoirs as would be used for carbon captured from point sources. They argue that air capture, like a conventional backstop energy technology, can provide an essentially unlimited quantity of mitigation at constant, high marginal cost. But because air capture would be completely uncoupled from the energy system, it would have two key advantages over any prior mitigation technology. First, air capture would take place in free-standing dedicated plants, and so would offer complete flexibility in siting, timing, and scale. Second, air capture would not be bound to any particular emissions stream, and so could be conducted at large enough scale to make any enterprise, nation, or human civilization as a whole, a net remover of carbon from atmosphere, rather than a contributor to it.

\section{The Benefits of Air Capture in a Dynamically Optimal Climate Response}

Assuming cost trends that make air capture competitive with conventional mitigation by late this century, the authors examine its significance using a dynamically optimizing integrated-assessment model. This analysis yields two important results. First, rather than atmospheric $\mathrm{CO}_{2}$ concentration reaching some elevated level at which it then stabilizes, optimal concentration time-paths reach some maximum value, then decline. This behavior arises from two characteristics of the cost and benefit functions assumed in the model, which are plausible although 


\section{E. A. PARSON}

by no means assured. First, mitigation costs decline with time, for reasons that have been familiar since Wigley et al. (1996) - mainly autonomous technological change and adjustment-rate costs - as well as the more questionable assumption in this analysis that baseline emissions stop growing in 2100. Second, climate damages are scaled to wealth, so the benefit of reducing concentration grows exponentially over time with the world economy. The interaction of these two factors gives an optimal concentration time-path that peaks then declines - a qualitative result that would apply whenever damages grow fast enough relative to mitigation costs. We would expect this to be the case, for example, if damages increase faster due to world population and economic growth than they decrease due to adaptation.

The authors find this result even with only a conventional backstop technology, but adding air capture to their analysis strengthens the effect: with air capture, optimal concentration declines rapidly through the $22 \mathrm{nd}$ and $23 \mathrm{rd}$ centuries. The reason for this difference is that conventional mitigation cannot reduce emissions below zero, so the rate of concentration decrease is limited to the natural rate of $\mathrm{CO}_{2}$ removal. Air capture has no such limit, however, so negative net human emissions can be as large, and concentrations fall as fast, as installed air-capture capacity can remove it. In the authors' analysis, optimal concentration converges to the preindustrial level because this is where they fix the zero-point of climate damages: choosing a different zero-point, or allowing this point to rise through adaptation, would instead yield a return to a higher ultimate concentration.

Their second main result follows from the first. Because air capture enables faster future reductions in atmospheric $\mathrm{CO}_{2}$ concentration in the future, it increases the reversibility of current emissions. Although significant irreversibilities remain, this effect reduces the value of early mitigation as a precaution against the risk that future climate damages will be large. Consequently, the prospect of future air capture reduces optimal near-term mitigation and total mitigation costs along the optimal path.

\section{How Would It Work? Technological Options in Political Context}

The authors' results describe changes that introducing the option of air capture makes to the optimal response to climate change. But introducing potentially attractive new options like air capture can influence the policy debate - and the decisions that emerge from it - in multiple ways, changing not just the responses to climate change that are optimal, but also the responses that are likely.

I consider these changes in likely responses, by examining the political economy of air capture. This requires moving outside the authors' dynamic optimization framework to consider the context in which responses to climate change will be argued, chosen, and implemented. From this perspective, pursuing air capture would be likely to have far-reaching effects on the politics of the aggregate response to 
climate change, and its likely effectiveness. These effects strongly distinguish air capture from both conventional mitigation and point-source carbon capture and sequestration.

Four potential effects are evident. One of these is an advantage: air capture can simplify the political problem of achieving mitigation by reducing the need for international cooperation. The other three effects are potential problems introduced or revealed by pursuing air capture, each pertaining to a different aspect of the response to climate change: the first concerns the effect of the prospect of air capture on near-term decision-making; the second questions whether a large future air-capture program can be as cheap and sustainable as the authors assume; and the third concerns potential harmful consequences if air capture is deployed at large scale. Although I refer only to air capture throughout, other geoengineering responses would face similar issues, with some variation arising principally from cost differences. I consider the four issues in turn.

Air capture has one important advantage in addition to those that the authors identify. Greenhouse-gas mitigation is a hard political problem in substantial part because of the degree of international cooperation needed to achieve it. Air capture could greatly simplify the problem by reducing the need for cooperation. Air capture would enable any nation to achieve a secure reduction in atmospheric $\mathrm{CO}_{2}$, independent of what others do. Nations dissatisfied with worldwide progress in mitigation could capture and sequester more $\mathrm{CO}_{2}$ than they emit, offsetting emissions increases of less committed nations. The authors' scenarios (their Figure 4) show air capture reducing atmospheric $\mathrm{CO}_{2}$ concentration by 1 to $2 \mathrm{ppm}$ per year for 150 to 200 years. Using their figures, a program to reduce atmospheric concentration by $1 \mathrm{ppm}$ per year would require about 28,000 cooling-tower structures, covering total land area of about $54,000 \mathrm{Km}^{2}$ (about half the area of Ohio, although the structures would be widely spaced so most of this land would remain available for other uses). With the authors' assumption that air capture costs decline to $\sim \$ 150 / \mathrm{tC}$ late this century, this program would cost roughly $\$ 300$ Billion/year, perhaps one-third of one per cent of United States GDP in the year $2100^{2}$ - an expenditure clearly within the fiscal capacity of the United States or some other large, rich nation. By 2100, it is even conceivable that such an effort might be within the capability of some coalition of large non-state actors.

The introduction of air capture is also likely to pose significant new challenges to successful management of global climate change. The first of these is that the prospect of future air capture introduces moral hazard into near-term mitigation decisions, encouraging more delay than is optimal and promoting excessive reliance on air capture or similar measures being successfully implemented in the future. Air capture expands the set of potentially attractive response options that are most likely to be relevant several decades in the future, or later. In a dynamic optimization framework, improving future options usually reduces the desirability of near-term mitigation efforts. In the authors' analysis, introducing air capture produces a modest, incremental reduction in the optimal amount of 


\section{E. A. PARSON}

near-term mitigation, coupled with a larger increase in later reductions through air capture.

But while the reduction in near-term mitigation implied by the authors' analysis may be small, the political process by which response decisions are debated and adopted is unlikely to respond in such a nuanced way. Analyses identifying better response options in the future reduce the political pressure for near-term efforts, by providing well-founded supporting arguments for those who oppose near-term efforts to any degree and for any reason. Consequently, focusing on the large gains available from promising but relatively distant technologies can starve attractive near-term options of policy attention and resources. Rather than generating an incremental reallocation of earlier to later effort in a mitigation plan that was optimal given prior information, introducing air capture may simply increase the likelihood that no real mitigation is done for several decades - a result that is not optimal in the authors' analysis or, likely, in reality.

This concern is not just hypothetical. Since implementing even attractive nearterm responses requires contentious political choices that distribute real costs, shifting the debate to attractive distant technological solutions is a tactic policy actors sometimes use to intentionally distract the debate from near-term choices. One prominent example is the recent focus in US policy on large-scale transformations of automobile technology such as hydrogen-powered fuel cells. While these options appear promising to develop for large-scale use in perhaps a few decades, they have in the meantime distracted from the substantial gains in fuel economy and reductions in greenhouse-gas emissions available from present technology (Keith and Farrell, 2003).

To the extent that focusing on attractive distant options like air capture causes us to reduce or delay near-term efforts - whether to a degree that some analysis suggests is optimal, or more - we make a commitment to relying on those future options working. This means not just that their performance and cost turn out about as good as presently projected, but also that future political and economic conditions are such that they are feasible and are judged acceptable for large-scale use, and that competent actors are present with the resources, authority, and incentives to deploy them. The less we do in the near term, the more we rely on the realization of all these benign future conditions - technological, economic, and political - that will enable more to be done, cheaper, later.

Is this a prudent gamble? The second challenge raised by air capture suggests that it might not be, because a future air capture program may be less sustainable than the authors' analysis requires it to be. As a consequence of how air capture would probably be funded and implemented, it may have less effective incentives for cost-cutting and innovation than either conventional mitigation or point-source carbon capture, and would be highly vulnerable to changing political and economic conditions - making reliance on such a future program as the basis for reducing near-term mitigation efforts even riskier. 
Conventional mitigation and point-source carbon capture gain their advantages over air capture from the fact that these approaches will mainly be implemented by private businesses, through investment and $R \& D$ decisions they take to pursue lower-carbon energy technologies. Businesses will make these decisions in response to incentives imposed by public policy. If the policies are sensibly designed and implemented - e.g., if they target emissions directly, allow flexibility in how firms meet their obligations, and include adequate monitoring and enforcement - they will provide incentives not just to improve environmental performance as required, but also to reduce costs and to pursue innovations to do it better and cheaper. Although greenhouse-gas mitigation policies would be unprecedented in their scale and their effect on the economy, several decades of experience with environmental regulation on other issues provide good guidance on how to design policies to put these incentives in place. If we follow this guidance, then policies that require mitigation by private firms are likely to motivate substantial cost reductions once they are enacted, in both the near and long term.

Moreover, such policies tend to persist once enacted, even under changing political and economic conditions. Enacting environmental policies always meets resistance: even well designed policies impose duties and costs on private actors, who generally prefer not to be so coerced. But for certain kinds of environmental policies, once the policies are enacted and firms have begun complying, there is little political pressure to weaken or reverse the policies. This asymmetry in the politics of environmental regulation - stiff resistance to enacting or tightening regulations, but little pressure to reverse them once enacted - arises from several factors. The most important is that when improvements in environmental performance are achieved through investments in innovations and cleaner technology, these costs are largely sunk. As investments and technology adjust around the new requirements and incentives for better environmental performance, these advances shape a new status quo - defined both in terms of the current state of technology from which further advances are pursued, and in terms of the shared perceptions and expectations of how responsible firms behave. Even firms that resisted new regulations, once they have improved their performance to meet the new obligations, can claim credit - reasonably - for helping to solve the problem.

These adjustment processes are substantially irreversible. Consequently, firms that have gone through them typically have little or no interest in the regulations being subsequently relaxed, even if only their narrowest commercial interests are considered. For example, it is most unlikely that any established firm could now benefit from re-introducing CFCs or weakening present emission controls on automobiles, given all the adjustments firms and markets have made to the present stringent requirements. Even in cases where a firm could benefit from weakening an environmental regulation, the cost to their reputation of openly advocating such weakening, and the response of competitors who are more strongly committed to environmental performance and who fear being undercut, make the prospects for a 


\section{E. A. PARSON}

successful reversal weak. In view of all these factors, environmental policies that achieve their effect by shifting private-sector investment and technology decisions tend to be highly resistant to attempts to weaken or reverse them. ${ }^{3}$

A large-scale air capture program, by contrast, would be less likely to benefit either from incentives for continued cost reduction and innovation, or from resistance to reversal. While conventional mitigation will be integrated into the technology and capital stock of private firms, air capture will be done in costly, dedicated "environmental factories" whose only output is an environmental benefit, and which are unconnected to the production of any private-market goods or services. This disconnection from private markets is another aspect of the decoupling of air capture from the energy system that Keith et al. identify. But while they correctly note that this decoupling will give air capture advantages of flexibility in implementation, it will also have large unfavorable implications for its cost and sustainability.

A major air-capture program would be the biggest public-works project the world has ever seen. Its funding would in all likelihood come from public treasuries, ${ }^{4}$ while its implementation would be through either direct government provision or contracting from private firms. If contracted from private firms, the relationship would be similar to military procurement of products for which no precise counterpart is sold in the private economy, and would likely face similar difficulties in sustaining strong incentives for performance and cost reduction. While well designed bidding processes, contract terms, and monitoring provisions can help, it is unlikely that any procurement process, or direct government provision, can generate these incentives as effectively as private markets do. With substantially weaker incentives for cost reduction, air capture would be less likely than conventional mitigation to benefit from the large cost declines over time that the authors assume.

Moreover, a successful air capture program must be sustained over periods that are extraordinarily long in political and economic terms: in the authors' analysis, the optimal climate response requires an air-capture program removing 1-2 ppm per year to operate continuously for 150-200 years. The large public expenditures such a program would require will always be politically vulnerable, no matter who builds and operates the facilities. Air-capture plants will provide only a pure global public-good, which will accrue over periods of several decades or longer. No matter how valuable these benefits are, there is unlikely to be any domestic constituency with a sustained material interest in supporting the associated large public expenditures - except the firms receiving the contracts, who are unlikely to be a serious political force. Consequently, funding for air capture will probably be a persistent target of budget-cutters whenever fiscal conditions are tight or public priorities shift. In view of this vulnerability, it may be quite imprudent to base present policies on the assumption that a large, costly future air-capture program can be established several decades hence and reliably sustained for 150 years or more.

These arguments for the vulnerability of air capture and its potential costliness, however, are based on the assumption that it is directly government funded. Might 
not some other way of organizing its provision and funding hold more promise of success? Two alternative forms of organization clearly merit consideration, although a preliminary examination suggests that both would face similar obstacles. One alternative would treat air capture facilities in the same manner as some jurisdictions treat highways, bridges, and other public infrastructure projects: entrust them to an independent public authority, funded either through a one-time capitalization or a dedicated revenue source such as a toll. Such an authority, with its specialized expertise and its insulation from larger-scale politics, would have significant advantages over regular government agencies in overseeing contractors and giving them sustained incentives for cost reduction and innovation. It would be unlikely, however, to significantly reduce the future political vulnerability of an air capture program, even once the program is established. The essential difficulty is that air capture, unlike highway or bridge authorities, does not provide a good or service of private value to identified users. Consequently, there is no natural way to connect its operations to a dedicated revenue source, like a toll, that can be securely insulated from general public budget politics. The closest approximation would be to earmark revenues from a relevant tax, such as one on greenhouse-gas emissions, but this could not attain the same level of security. Even more seriously, an air capture authority would be unlikely to gather a constituency, like highway users, with a strong material interest in its continued operations. Consequently, it will always be possible - and attractive to many - to save money by shutting down air capture operations and reclaiming the operating costs for other public priorities.

A second alternative would seek to privatize air capture. This would require integrating air capture into some larger-scale regulatory scheme, under which private emitters bear an obligation to reduce emissions that they may choose to meet either through air capture or conventional mitigation. This approach could promote efficient trading off of contemporaneous mitigation opportunities, and would provide incentives for cost reduction: we would expect to see air capture operating if and when its costs decline enough, and conventional mitigation proceeds far enough, that air capture is competitive with the remaining mitigation opportunities. This possibility would be allowed by any well designed system of tradable emission permits that counts all emissions and secure sequestration equivalently. No explicit policy supporting air capture would be needed, beyond ensuring that the removals achieved by air capture are fairly credited.

But such trading of future air capture against concurrent mitigation would not capture the largest benefit of air capture that the authors identify. They project that large-scale deployment of air capture will come late this century and beyond, when it will exceed concurrent emissions and so drive atmospheric concentrations rapidly downward. The major benefits of air capture consequently come not from displacing more costly concurrent mitigation, but from displacing mitigation that would otherwise have been conducted decades earlier. Allowing such displacement to occur within a private tradable-permit system would require creating multidecade emissions budgets that let emitters avoid near-term obligations by promising 


\section{E. A. PARSON}

reductions decades in the future. In view of all the ways such promises could be broken - e.g., bankruptcy - it is most unlikely that such a system could be made acceptably secure.

In sum, these two alternative models for organizing air capture could strengthen incentives for cost reduction, but would not overcome the insecurity of sustained future performance. The first alternative would be as vulnerable as direct public provision to shifting policy priorities and budgetary conditions; the second would simply replace that insecurity of public performance by an insecurity of private performance at least as severe. Neither alternative would appear to significantly reduce the risks of basing current decisions on the assumption of a cheap, largescale future air capture program sustained for more than a century.

The third concern with air capture pertains to the consequences for international politics if a large-scale air capture program is successfully implemented. A largescale air capture program would represent a substantial increase in the explicit, active exercise of human control over the global atmosphere, allowing for the first time the possibility of intentionally either increasing or decreasing radiative forcing. This expansion of the domain of environmental properties for which human activities are explicitly responsible would, among other changes, create substantial new possibilities for conflict over how we should use this new power: in what direction, how far, and how fast should we steer atmospheric $\mathrm{CO}_{2}$ concentration?

In their analysis, the authors assume that the optimal $\mathrm{CO}_{2}$ concentration for human welfare is the pre-industrial level of $280 \mathrm{ppm}$, while acknowledging that adaptation to higher concentrations during the 21 st century could raise the ideal level. Opponents of near-term mitigation are already questioning this assumption, however, arguing - perhaps insincerely, but with some foundation - that there is no reason to assume the global climate of two centuries ago is necessarily ideal for human welfare, even without considering potential adaptation to future changes. The issue is complex, but the obvious preference of many temperate and highlatitude citizens for warmer climates provides some evidence that optimal $\mathrm{CO}_{2}$ concentration may be somewhat higher than the pre-industrial level.

Moreover, given large disparities among world regions in projected climate impacts, adaptation potential, and resources - not to mention culture and preferences - it is likely that citizens of different regions, or even different groups within a region, will disagree over the preferred level. As advancing knowledge and the experience of continuing climate change make the consequences for specific groups and regions of alternative $\mathrm{CO}_{2}$ concentrations clearer, such disagreement could rise to the level of sharp inter-regional conflict. Such conflicts have had at most a marginal presence in climate-policy debates thus far, but each increase in explicit human ability to manipulate the climate is likely to make them more central and more acute - particularly if the actions in question lie within the capability of a single nation acting unilaterally. In a worst-case scenario, states might not only pursue contrary policies to move the global climate in their preferred direction, but might begin to interpret any destructive weather or climate extreme they 
experience as the responsibility, perhaps even the intention, of some other state a situation frighteningly reminiscent of early cold-war worries about intentional weather modification as an act of war (NRC, 1966).

\section{Conclusions}

In theory, having more options to choose from always makes you better off: if it is advantageous to use a newly identified option, you can benefit; if not, you can do what you would have done otherwise and be no worse off. But in public policy making - perhaps especially for issues with such far-reaching implications and long time horizons as climate change - the set of options considered influences the decision process in more complex ways, with implications for the tradeoff between early and delayed action, the distribution of costs and benefits, and the prospects for deadlock and conflict.

The growing prominence in the climate-change debate of technically attractive but temporally distant prospects like air capture may hinder development of an effective climate-change response in three ways: legitimating the current deadlock over mitigation by providing good reasons that delaying action is preferable, even if these apply only within a highly idealized decision-making framework; misleading early decision-making by promising more for future technical prospects than they can likely deliver in practice; and sharpening the potential for international conflict over climate change.

These risks do not inhere in the technical options themselves: as Keith et al. argue, air capture deployed optimally in an integrated response to climate change brings clear benefits. Rather, the challenges arise from how these options interact with likely biases, conflicts, and other pathologies of choice in a policy setting. The essential problem is that while introducing these options improves the optimal response, it may also move the likely response further away from optimality.

These decision challenges do not, of course, imply that air capture should not be seriously considered and investigated. In any case, we cannot avoid these decision challenges by pretending to ignore the technical options that raise them. Capabilities like air capture and other forms of geoengineering are obvious upon systematic examination of the climate-change issue, and so will remain available for actors to promote in the policy debate. Indeed, because the increasing identification of such responses is a consequence of the continued expansion of human activities and capabilities to influence planetary-scale processes - the same driving forces that are generating the increase in number, severity, and complexity of our planetaryscale environmental burdens - such options are only likely to grow more numerous and more salient, and to gather more support.

Whether air capture - or any other promising form of active intervention in planetary-scale processes - should be a significant part of our response to climate 


\section{E. A. PARSON}

change is not a question that can be sensibly approached piecemeal, one technology at a time. Rather, the steady growth of both our capabilities and our environmental burdens, and the shrinking maneuvering room we have to make decisions to limit climate change, will increasingly compel us to face more systematic questions about how to respond than we have so far. Can we continue to rely on specific technical correctives for each problem as it arises - whether these are changes in production processes to further reduce environmental burdens per unit of output, or direct environmental interventions to offset those burdens like air capture? Alternatively, can we continue to rely on narrowly drawn policies to motivate reductions in whatever specific forms of production and consumption pose the clearest immediate risks? Or must we somehow find a way to address the larger-scale question of limiting the aggregate scale of human population and economic activity, and seek to identify some means to achieve this that is compatible with humane, democratic states that value individual liberty? Each new proposal for a seemingly attractive geoengineering response to climate change illustrates how essential it is to address these larger-scale questions, but after nearly twenty years of policy discussions about climate change it appears that our decision-making processes and institutions remain gravely inadequate for this task.

\section{Acknowledgements}

I thank Jill Horwitz, Dana Jackman, and David Keith for helpful comments and discussion.

\section{Notes}

\footnotetext{
${ }^{1}$ Although several types of intervening option were discussed in scientific reports as early as the 1960s, these essentially disappeared from consideration as climate change began to attract policy attention in the late 1980s. This category of responses was first explicitly distinguished from emissions reduction and adaptation by Schelling (1983), who called them "countervailing modifications."

${ }^{2}$ Based on 1 ppm $\mathrm{CO}_{2}=2.16 \mathrm{GtC}$; costs occur in some future year but are measured in 2005 dollars; United States average annual real GDP Growth through 2100 is 2\%; reduction of $1 \mathrm{ppm}$ per year is measured from the concentration trend that would have occurred given world net anthropogenic emissions other than the specified air capture program.

${ }^{3}$ Note that this argument does not apply to all environmental policies. Policies that limit land development or resource exploitation activities, or that require costly operational changes that are not embedded in new capital or technology, impose continuing operating costs that can be avoided anytime by weakening the policies. As a result, such policies more often face attempts to weaken or reverse them, like recent attacks on the Endangered Species Act and on regulations for hydrocarbon exploration and development.

${ }^{4}$ Voluntary provision would also be possible, as suggested above, but the scale of this funding source would probably be much more limited.
} 
REFLECTIONS ON AIR CAPTURE

\section{References}

Keith, D. W.: 2000, 'Geoengineering the climate: History and prospect', Annual Review of Energy and Environment 25, 245-284.

Keith, D. W. and Farrell, A. E.: 2003, 'Rethinking hydrogen cars', Science 301, 315-316.

Keith, D. W., Ha-Duong, M. and Stolaroff, J. K.: 2006, 'Climate strategy with $\mathrm{CO}_{2}$ capture from the air', Climatic Change 74(1-3).

Parson, E. A. and Keith, D. W.: 1998, 'Fossil fuels without $\mathrm{CO}_{2}$ emissions', Science 282, 1053-1054.

Schelling, T. C.: 1983, 'Climate change: Implications for welfare and policy', Changing Climate, Report of the Carbon Dioxide Assessment Committee, US National Research Council. National Academy Press, Washington DC, 449-482.

Schlamadinger, B. and Marland, G.: 2000, Land Use \& Global Climate Change: Forests, Land Management, and the Kyoto Protocol, Pew Center on Global Climate Change, Washington DC.

U.S. National Research Council: 1966, Weather and Climate Modification National Academy Press, Washington DC.

Wigley, T. M. L., Richels, R., and Edmonds, J.: 1996, 'Economic and environmental choices in the stabilization of atmospheric $\mathrm{CO}_{2}$ concentrations', Nature 379, 240-243.

DR. EDWARD A. PARSON

School of Law and School of

Natural Resources and the Environment

Hutchins Hall 432

University of Michigan

625 South State Street

Ann Arbor MI 48109-1215

E-mail:parson@umich.edu 